\title{
Escuta, construção, composição
}

\section{Listening, construction, composition}

Rogério Vasconcelos Barbosa ${ }^{1}$

UFMG

rvb@musica.ufmg.br 


\section{Resumo}

O texto discute o processo de composição de quatro obras do autor utilizando as noções de "material musical" e "modelo". Modelo seria uma combinação de traços formais que se extrai de um material musical com o objetivo de se projetar em outro contexto. Os modelos envolvem princípios de organização que se aplicam a diferentes aspectos da dimensão formal da música. São analisados diversos trechos de peças do autor a partir das mesmas noções. Discute-se também a utilização da modelagem computacional (CAC) no processo de composição.

Palavras-chave: Composição; modelo; material musical; escuta; CAC.

\section{Abstract}

The paper discusses the composition process of four pieces by the author, using the notions of 'musical material' and 'model'. A model would be a combination of formal features that are extracted from a musical material to project itself in another context. The models involve principles of organizations that apply to different aspects of the formal dimension of music. Several excerpts from the author's pieces are analyzed based on the same notions. The use of computational modeling (CAC) in the composition process is also discussed.

Keywords: Composition; model; musical material; listening; CAC. 


\section{I}

O modelo hilemórfico é associado ao pensamento de Aristóteles e se refere à moldagem/modelagem de um material por uma forma. Assim, o artesão modela o barro segundo uma forma que tem na mente - por exemplo, a de um vaso. A modelagem é justamente a transformação de uma matéria homogênea e maleável - no caso, o barro -, de modo a alcançar uma forma previamente escolhida.

Há alguns aspectos que merecem ser discutidos nessa transformação. Um deles é que as matérias não são completamente neutras e homogêneas e, por isso, acabam interferindo no processo de modelagem. Assim, haveria direções de transformação mais aptas do que outras. Dizendo de outro modo, a matéria resiste à influência de forças em certas direções, e, por vezes, o material pode quebrar-se ou ainda não reter a forma desejada. A preparação de um material implica justamente a tentativa de torná-lo o mais homogêneo e neutro possível, de modo que esteja apto a ser moldado em diferentes tipos de formas.

A homogeneidade não é nunca completa. O exemplo do barro faz pensar em uma matéria meio sólida, meio líquida, em que a natureza líquida refletiria a maleabilidade, e a sólida, a capacidade de reter uma forma. Assim, haveria um equilíbrio desejável entre as naturezas líquida e sólida para uma boa situação de modelagem. Após a modelagem, o desejável seria justamente mudar o equilíbrio, intensificando a natureza sólida para fixar a forma desejada.

Por outro lado, não se parte sempre de uma forma previamente definida em todos os detalhes para ser usada na modelagem. Muitas vezes, parte-se de uma forma genérica, e os detalhes surgem justamente no decorrer do trabalho. Assim, a resistência do material pode contribuir para mudanças de detalhes que vão se tornar decisivos na forma final. Por exemplo, um artesão que esculpe a madeira pode aproveitar um veio para definir um ponto ideal de corte ou entalhe.

Na composição musical, pode-se falar também de um material musical e de modelos que constrangem esse material a assumir determinada configuração ou forma. O compositor habitualmente parte de materiais relativamente neutros e homogêneos, susceptíveis de serem transformados de diferentes modos. Sobre esses materiais são projetados modelos de organização que os transformam de variadas maneiras.

Mas o material musical não é neutro nem homogêneo. Os instrumentos musicais, por exemplo, já trazem em sua construção princípios de organização que definem potências do material musical. As escalas previstas em sua construção definem relações frequenciais preestabelecidas. Assim, pode-se dizer que os materiais musicais já estão, de certo modo, previamente preparados. Sobre esse material protoelaborado, os compositores projetam suas formas, e esse processo pode ser bastante complexo. Há diversos modelos de organização do material musical que são compartilhados e retornam em diferentes trabalhos, por exemplo, combinações instrumentais típicas, processos har- 
mônicos, protótipos formais etc. Muitas vezes, o compositor dialoga com esses modelos da tradição, aproximando-se ou afastando-se de referências anteriores. ${ }^{2}$

"Modelo" seria uma combinação de traços formais que se extrai de um contexto com objetivo de se projetar em outro. Esse conjunto é restrito e limitado e certamente será transformado no momento de se ajustar a um novo material. Assim, por exemplo, as cadências harmônicas tonais são retomadas em obras de inúmeros compositores, mas a cada vez a condução das linhas melódicas se altera em alguma medida, ajustando-se à composição específica.

Há modelos que se aplicam a diferentes níveis de organização formal da música. $O$ exemplo das cadências faz pensar em janelas temporais de curta duração, mas, se pensarmos em protótipos formais - como as danças barrocas ou a forma sonata -, os modelos considerados abarcam janelas temporais muito mais extensas. No caminho inverso, os diferentes tipos de ornamentação barroca são modelos que transformam as linhas melódicas em uma dimensão temporal muito mais breve, tornando-as mais elaboradas e complexas. Os processos de organização podem voltar-se tanto para o detalhe quanto para os grandes blocos formais. Pode-se dizer que em uma composição há modelos de diferentes naturezas que se interpenetram e que o resultado musical é complexo; muitas vezes os elementos combinados podem tornar-se indiscerníveis e mesclados na trama da composição. O trabalho do compositor envolve a assimilação desses princípios ordenadores da tradição musical e sua adaptação a novos contextos. Trata-se de criar combinações de modelos que se articulem de forma rica, flexível e expressiva.

\section{II}

$\mathrm{Na}$ origem de meus processos criativos está frequentemente a memória de uma passagem musical que me estimula a buscar derivações novas. Algumas ideias ouvidas em peças de outros compositores ficam, de certo modo, aprisionadas em minha imaginação, que vai, aos poucos, transformando-as em algo diferente. Por vezes, uma certa experiência de escuta me lança em um espaço expressivo intenso. A composição pode ser, então, uma tentativa de reviver aquele momento ou aquele mundo. Mas não se trata de copiá-lo. Ao contrário, seria uma tentativa de resgatá-lo, de modo a percorrê-lo de outras formas, ou ainda de explorar outros caminhos possíveis em sua topografia. Assim, um ponto de partida frequente é o estudo de trechos da produção musical contemporânea.

Para isso, utilizo ferramentas tecnológicas de modo a capturar e elaborar traços distintivos dos exemplos musicais estudados. Algumas das características do material analisado são codificadas em um ambiente de programação particular - linguagens

\footnotetext{
2 "Essas estruturas técnicas composicionais pré-formadas, intermediárias entre, de uma parte, as restrições que as propriedades físicas e psicológicas do material fazem pesar sobre sua utilização e, de outra parte, as exigências do projeto estético, entre a resistência do real concreto do som e as intenções do compositor (oposição pertencente ao velho dualismo matéria-forma), têm uma enorme importância na música ocidental; elas evoluíram historicamente da Idade Média ao século XX: modos gregorianos, consonâncias polifônicas, cadências tonais etc." (DUCHEZ, 1991, p.61).
} 
Lisp (softwares $\mathrm{PWGL}^{3}$ e OpenMusic ${ }^{4}$ ) e, mais recentemente, Python -, o que permite a criação de variações mais ou menos afastadas do modelo original. Frequentemente há uma fase de composição semiautomática, com aplicação dos algoritmos desenvolvidos no modelamento. Em seguida há outra fase mais livre, não sistemática, onde meu trabalho consiste em esculpir o material gerado anteriormente de um modo fantasioso e intuitivo, o que transforma bastante o resultado final, muitas vezes tirando a clareza dos processos de organização iniciais. Eu diria que o modelamento abre um caminho que a seguir precisa ser descoberto e explorado por uma imaginação livre e curiosa. Insisto nessa ideia porque a utilização de uma formalização algorítmica no plano técnico pode sugerir que a racionalidade do processo seria suficiente para gerar um resultado artístico interessante. Não acredito nisso. Ao contrário, penso que o trabalho artístico requer uma combinação de componentes racionais e intuitivos e que muitas escolhas do compositor permanecem, em grande medida, inexplicáveis. Não se trata de abrir mão da racionalidade nos modos de se pensar a arte, mas de reconhecer nela (na arte) uma dimensão insondável, que é parte de sua riqueza. A experimentação com o material pode conduzir ao encontro de soluções interessantes e imprevistas no início do processo criativo.

A seguir, apresentarei alguns exemplos de peças minhas que dialogam, de modo mais ou menos claro, com outras do repertório do século XX, assim como farei alguns comentários sobre o processo de modelagem computacional de alguns procedimentos composicionais.

\section{III - Tensibilia II - mov.2 harmônicos}

O segundo movimento da peça Tensibilia II, para quarteto de violões, utiliza um modelo rítmico inspirado em Elliott Carter. Trata-se do polirritmo estrutural. ${ }^{5} \mathrm{~A}$ ideia básica desse modelo consiste em superpor dois pulsos lentos com relações complexas de proporção temporal. Após essa primeira etapa, as durações correspondentes aos pulsos são subdividas (ornamentadas) de modo a se obter uma figuração variada. Em consequência da relação complexa entre as velocidades, obtém-se um resultado rítmico que se caracteriza por uma fluidez temporal e ausência de uma métrica clara.

Habitualmente, Carter utiliza um ciclo completo de repetições das durações do polirritmo, de modo a obter uma nova sincronia dos ataques próximo ao fim da peça em questão. Parti de uma proposta ligeiramente diferente: associei trechos da música (blocos temporais ou seções) a diferentes polirritmos. Cada trecho utiliza um novo polirritmo, com velocidades diferentes do anterior, e uma de suas linhas rítmicas se inicia precisamente no ponto em que o polirritmo anterior termina. Assim, há vários blocos sucessivos, com polirritmos diferentes, terminando sempre com uma sincronia dos ataques dos dois planos (entrada em fase).

\footnotetext{
3 Laurson, Kuuskankare e Sprotte (2006).

$4 \quad$ Agon, Assayag e Bresson (1998).

5 Long-Range Polyrhythm (LINK, 1994).
} 

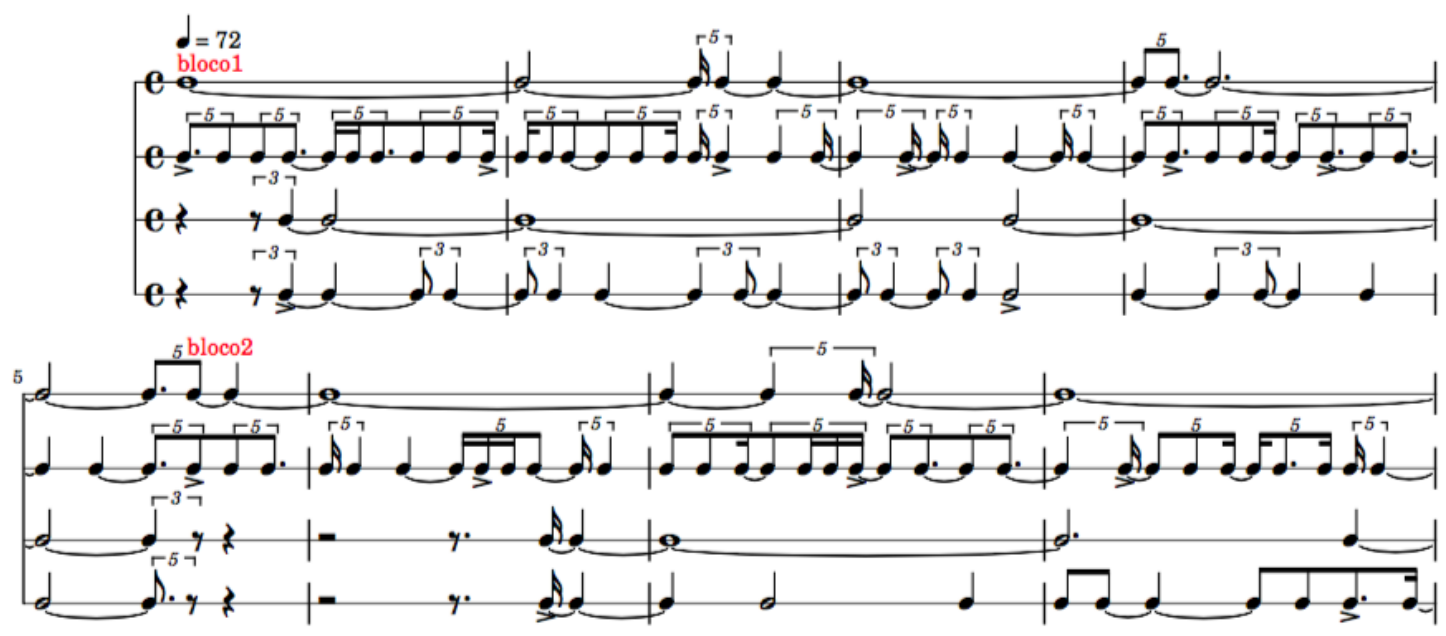

Fig. 1: Excerto do polirritmo de Tensibilia /I - mov.2

$\mathrm{Na}$ Fig. 1, as pautas 1 e 3 (contando-se do alto para baixo) ilustram os pulsos fundamentais; as demais, a subdivisão rítmica. A duração do pulso da pauta 1 equivale a 31 quintinas de semicolcheia (5.16 segundos no andamento $72 \mathrm{MM}$ ); a da pauta 3, 26 tercinas de colcheia (7.22 segundos).

Foi desenvolvido um algoritmo no programa PWGL que gera o polirritmo a partir de algumas informações (tipo de subdivisão da semínima, multiplicador, duração máxima e mínima dos pulsos em segundos). O algoritmo permite também recortar/extrair um fragmento determinado do polirritmo para sua utilização na composição. $O$ interesse do algoritmo é facilitar a experimentação de diferentes possibilidades, devido à complexidade do processo quando realizado manualmente.

Com relação à subdivisão dos pulsos para se obter a figuração de superfície da música, há duas etapas: na primeira, a duração é subdividida por proporções simples (por exemplo, 2 para 3 ou 1 para 2); na segunda, a subdivisão é livre, depende de decisões não automáticas, ligadas à escuta do trecho em questão.

A cada linha do polirritmo, foi associada uma diferente morfologia: linha melódica ressonante (sobre o timbre, falarei mais à frente) versus arpejos. A linha melódica evolui seu perfil tipicamente descendente para uma ondulação no registro. Comparem-se os compassos iniciais com o trecho dos compassos 21 a 24, na Fig. 3.
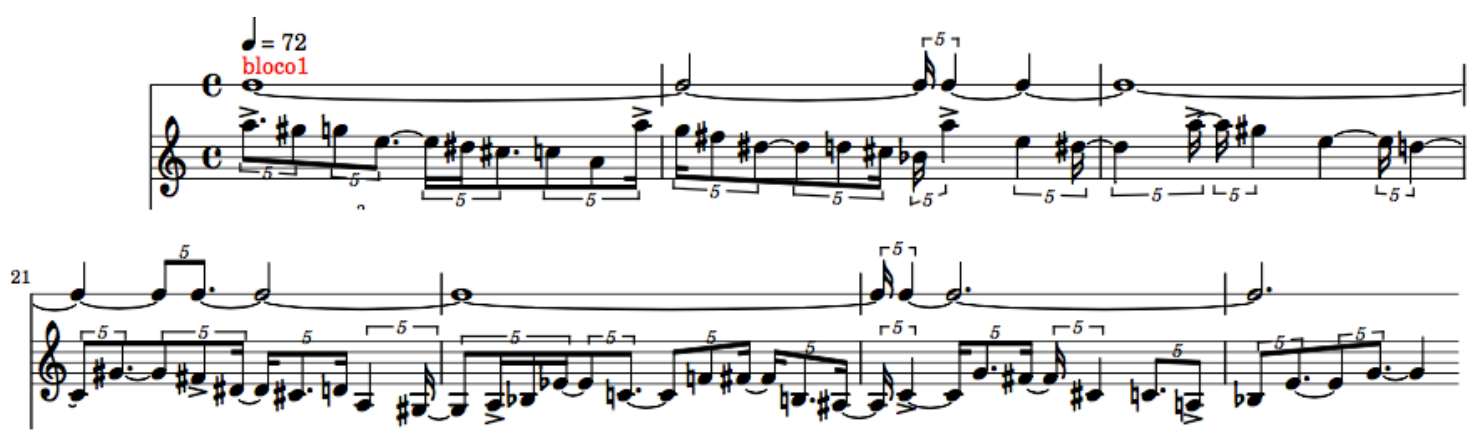

Fig. 3: Evolução do perfil melódico 
A harmonia utiliza um grupo de conjuntos aparentados, com o objetivo de criar uma cor interválica homogênea. São eles, seguindo a denominação da Set Theory: 7-16, 7-Z18, 7-19, 7-21 e 7-22. Esses conjuntos, em diversas transposições e inversões, se sucedem de modo a constituir campos harmônicos em transformação progressiva. Os campos também podem ser formados por combinações parciais dos conjuntos anteriores, e sua aplicação utiliza um algoritmo que os molda a perfis melódicos específicos, ou seja, utilizam-se as alturas do campo harmônico para gerar uma curva melódica definida. O princípio de funcionamento é traduzir a sequência de alturas do perfil desejado em uma lista de números, contando-se a partir de zero para o som mais grave. Em seguida, esses números são associados a outras notas, no caso, aquelas do campo harmônico desejado, contando zero para a nota mais grave (ou para a mais aguda, no caso de uma inversão do perfil inicial). O requisito necessário é que o campo tenha tantas notas diferentes quanto o perfil melódico. $O$ objetivo desse algoritmo foi explorar o potencial de uma linha melódica específica, extraída do solo de trompete presente na introdução de A Symphony of Three Orchestras, de Elliott Carter (1978). Essa linha explora a ondulação melódica em diversas escalas, desde pequenas oscilações a grandes curvas, e foi utilizada como um modelo de onde foram extraídas diversas curvas melódicas presentes em Tensibilia.

Considero que a relação do modelo com a minha peça é sutil, devido às mudanças das alturas específicas - em Tensibilia, as alturas são derivadas dos campos harmônicos - e também devido à distribuição da linha melódica resultante entre os quatro violões, formando uma textura heterofônica.

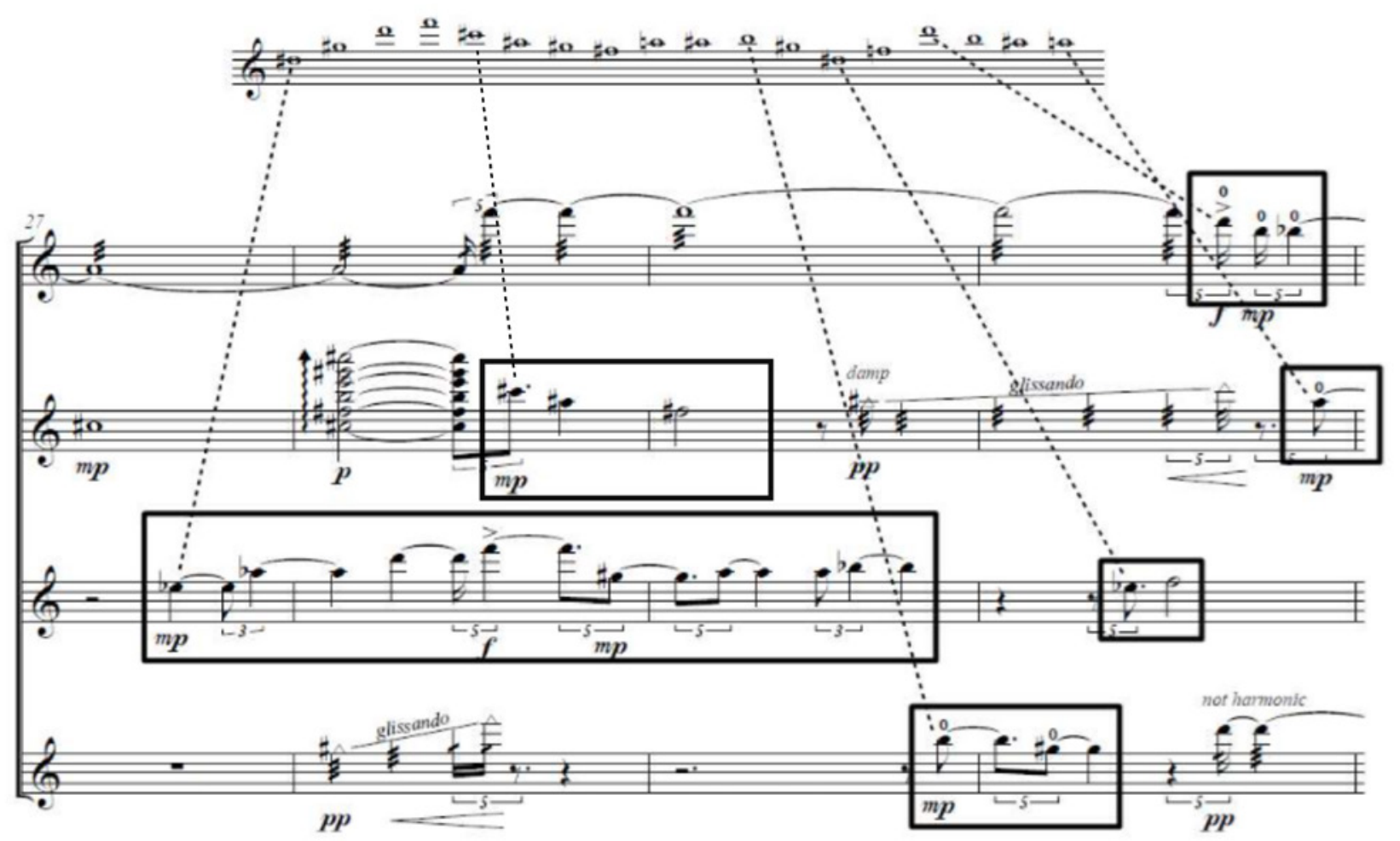

Fig. 4: Linha ondulante distribuída entre os violões 
O segundo movimento de Tensibilia I/ explora os harmônicos naturais do violão. Para aumentar o leque de harmônicos disponíveis, os violões I, II e III utilizam capotastos nas casas III, II e I, respectivamente. Com isso, considerando-se as notas disponíveis nos quatro violões, obtém-se a escala cromática de harmônicos naturais dentro de certo registro. Isso possibilita a divisão da linha melódica gerada pelos diversos campos harmônicos entre os violões, mantendo-se a ideia de cada nota ter um timbre de harmônico. Por sua vez, a linha torna-se ressonante, deixando uma aura sonora ao redor dos diversos ataques. Os violões funcionam como um único macroinstrumento, com quatro corpos vibrantes separados no espaço.

Outras morfologias sonoras são usadas, buscando uma "orquestração" mais colorida. Os tremolos criam uma sonoridade contínua, agindo como um pedal sonoro que contrasta com o plano mais articulado da linha ressonante e dos arpejos. Os glissandos reforçam a direcionalidade de alguns gestos melódicos, acentuando a chegada em alguns pontos específicos e criando certa dramaticidade, mesmo em um contexto construído com grande delicadeza. A performance requer um controle cuidadoso do tempo, com rubatos suaves sublinhando as seções internas, de modo que possa ser percebida uma certa flutuação no ritmo, quase como se não houvesse nenhuma pulsação subjacente. Essa foi a imagem inicial que impulsionou o processo de composição, uma nuvem ressonante de harmônicos sucedendo-se ritmicamente de modo flutuante.

\section{IV - u(celli - mov.2 luna}

O quarteto de violoncelos u(celli tem três movimentos. Vou me concentrar em descrever o processo de composição do segundo movimento, luna.

O ponto de partida da composição foi a escuta da peça ... Ruhe sanft..., para voz gravada e quatro violoncelos, de Klaus Huber (2010). A sonoridade e a textura me impressionaram, assim como a atmosfera delicada e silenciosa.

Não tinha a partitura em mãos e, por isso, resolvi partir de uma análise de um excerto da gravação (cerca de 90 segundos). Após importar o áudio no software Sonic Visualiser (CANNAM; LANDONE; SANDLER, 2010) e gerar um sonograma de referência, inseri manualmente marcadores temporais em alguns ataques importantes.

Em seguida, os marcadores foram exportados e tratados por um algoritmo no PWGL, de modo a serem convertidos em notação musical (quantização simples para metrônomo semínima $=46$ ). Esse material rítmico foi analisado para servir de referência na criação de ritmos similares. É importante destacar que meu interesse era obter variações do original. O caminho tomado foi, por meio da análise das durações do original, construir um modelo que permitisse a geração de diversos ritmos diferentes, porém com características similares. Esse modelo considerava alguns aspectos do original e desprezava outros, sempre que isto facilitasse a criação de uma certa lógica organizacional.

As distâncias entre ataques dos marcadores equivalem, em número de semicolcheias, a (6 78152111361215229339162471263152716 14). Há padrões claros nessa sequência. Para evidenciá-los, fiz uma divisão das durações em três registros: 
durações curtas (2 a 8 semicolcheias), médias (11 a 15) e longas (19 a 24). Convertendo a lista de semicolcheias anterior em símbolos c (durações curtas), $m$ (médias) e l (longas), obtive a seguinte lista de símbolos: (c c c m l m c c m m l m c c m m l c m c c c c c c $\mathrm{m} \mathrm{m}$ ). Extraí da sequência três tipos de padrões de ataques: o tipo_1 era caracterizado pela sequência de durações curtas (1 a 4 ataques seguidos), médias (1 a 2) e longa (1); o tipo_2, pela sequência de durações curtas (1 a 4 ataques seguidos), médias (1 a 2), longa (1) e média (1 a 2); o tipo_3, pela sequência de durações curtas (1 a 4 ataques seguidos), médias (1 a 2), curtas ( 1 a 4 ) e médias (1 a 2). A partir desse esquema, passei à geração de novos padrões para formar o ritmo de base do movimento. Há um processo de experimentação e seleção de versões mais interessantes, pois o algoritmo gera soluções com grande diversidade.

O passo seguinte do processo envolveu uma modelagem da textura e do timbre. Inicialmente foi preciso determinar quais instrumentos participavam de cada ataque. Foi utilizada a técnica de programação com restrições, de modo a criar diversidade na sequência. Por exemplo, a cada quatro ataques seguidos, as combinações deveriam mudar, tanto de instrumentos selecionados quanto de densidade (1 a 3 instrumentos por ataque). Um exemplo de solução possível calculada pelo algoritmo seria, por exemplo, ((1 4) (2) (3) (1 2) (4) (1 3) (1) (2 3 4) (1 4) (3) (1) (1 2 3) (3 4) (3) (2 4) (1 3 4) (3) (2) (3 4) (1 2 3) (4)), onde cada sublista indica os números dos instrumentos envolvidos no ataque em questão. O segundo passo foi atribuir a cada instrumento participante do ataque um tipo de articulação dentre as seguintes: pizz., pizz. Bartók, arco batt., legno batt., arco stacc., balzato, acento/trem., arco liso, trem., gliss. harm., arco sfz p. Para a seleção dos tipos de articulação, também foi utilizada a programação por restrições, novamente para obter variedade. Além disso, novos timbres ruidosos (arco no cavalete, pizzicato atrás do cavalete) foram incorporados à partitura final, embora estivessem ausentes do algoritmo.

A Fig. 5 ilustra a diferença entre a versão algorítmica da textura (parte superior) e o resultado final da partitura (parte inferior), que exigiu uma manipulação livre do material bruto e bastante imaginação para superar a rigidez do automatismo. 


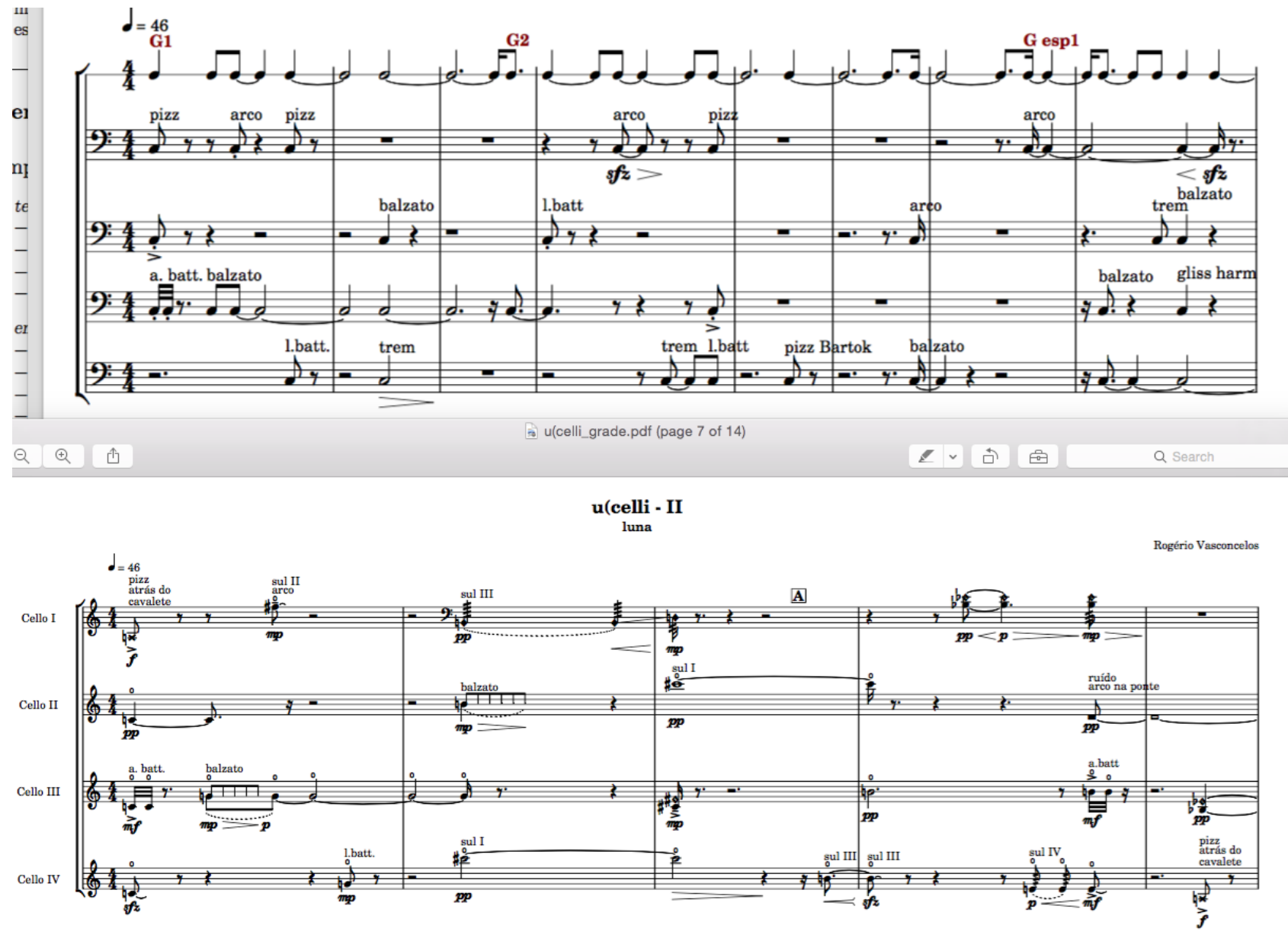

Fig. 5: Comparação do resultado do algoritmo com a versão final da partitura (compassos iniciais)

Com relação à harmonia, o movimento organiza-se pela sequência de seis transposições do mesmo conjunto 8-9 (transposições 5, 2, 4, 1, 3 e 0). A partitura não utiliza os conjuntos completos, apenas explora a coloração intervalar como meio de coesão.

\section{V - Passos - mov.2}

A peça Passos, para piano e percussão múltipla, tem dois movimentos. Cada um deles foi composto como uma expansão de uma miniatura escrita originalmente para piano. Neste texto, vou me deter nos comentários sobre o segundo movimento, caracterizado por uma rítmica pulsada.

A peça que deu origem ao movimento II explora o registro extremo grave do piano. Há duas linhas rítmicas: os ataques da primeira linha acontecem na primeira ou terceira semicolcheias de cada tempo; os ataques da segunda, na segunda ou quarta semicolcheias de cada tempo. Com isso, gera-se uma relativa oposição entre as linhas rítmicas, baseada na métrica. Observar na parte superior da Fig. 6 o início da partitura de piano. Na parte central da mesma figura apresenta-se a partitura de piano e percussão (movimento II, de Passos). Pode-se observar uma redistribuição dos ataques entre as mãos do pianista, buscando melhor adaptação ao gesto instrumental. 

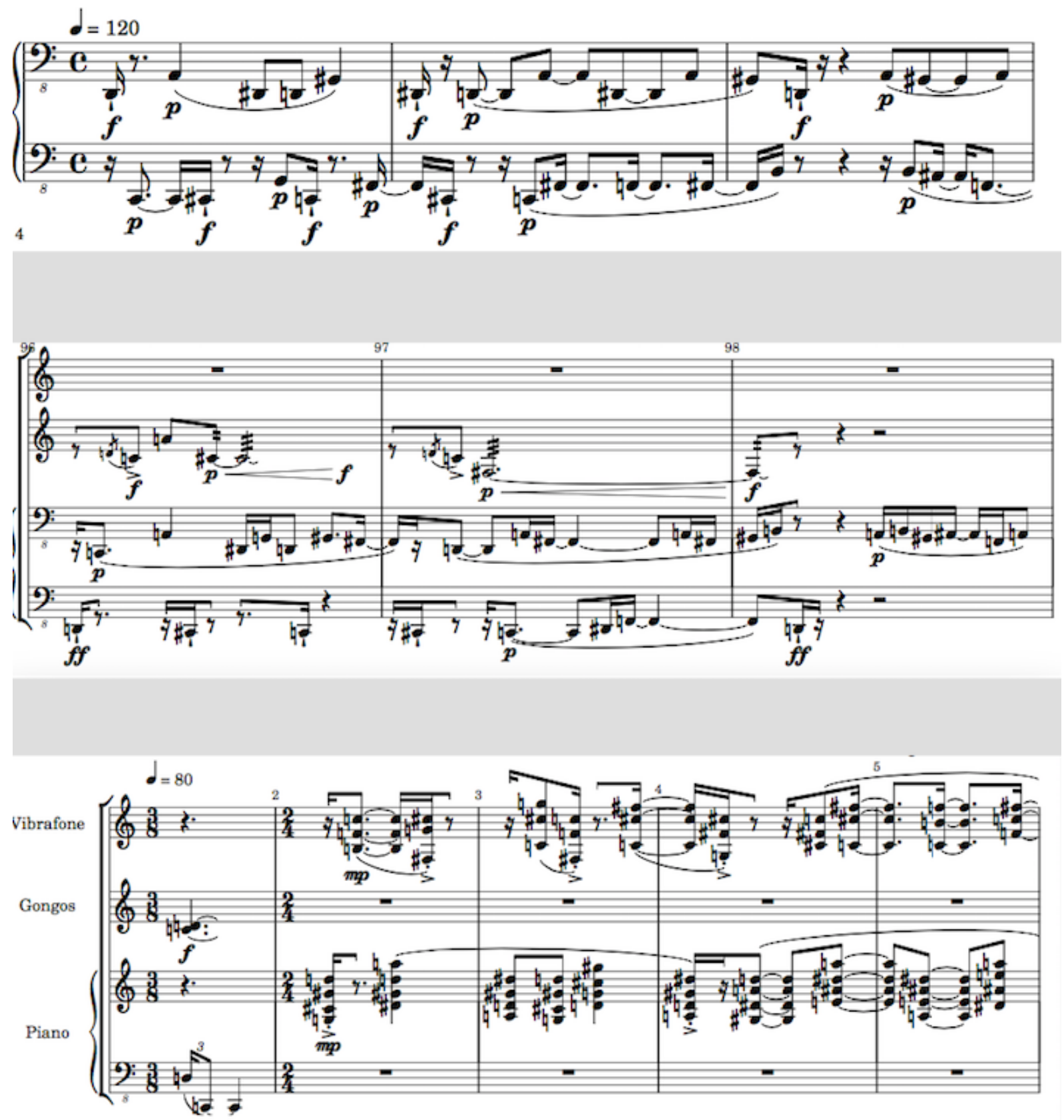

Fig. 6: Linhas rítmicas em oposição métrica (acima). Mesmo trecho na versão de piano e percussão (no centro) e elaboração da ideia (abaixo).

Na parte inferior da Fig. 6, pode ser observada uma primeira elaboração da mesma ideia, a partir do compasso 2. O piano executa a linha rítmica apoiada no tempo, enquanto o vibrafone, a linha do contratempo. As notas agudas de cada acorde são as mesmas alturas (em diferente registro) da versão original de piano. Entretanto, há expansão harmônica, ou seja, cada nota é transformada em um acorde específico, com destaque para intervalos de semitom, quarta justa e trítono.

Essa elaboração do material vai preceder o material original. A sonoridade grave do piano combinado aos gongos pareceu mais adequada ao fechamento do movimento. Como há grande contraste dessa versão com o final, uma segunda elaboração $\otimes$ um 
gesto de pontuação no grave (compasso 1) $\otimes$ acabou sendo criada, de modo que ao mesmo tempo articula entre si os blocos mais agudos e, por outro lado, antecipa o registro grave do final do movimento.

A partir da letra A, os blocos agudos serão elaborados com variações rítmicas. Os acordes, anteriormente em blocos, passam a ser arpejados. Além disso, começa a surgir outro tipo de contraste rítmico entre os planos, baseado na polirritmia: o piano utiliza sextinas de semicolcheia, contra as semicolcheias regulares do vibrafone. É importante observar que os apoios métricos de cada instrumento continuam a respeitar as posições originais de cada uma das linhas rítmicas (tempo $x$ contratempo), de modo que os instrumentos estabelecem entre si uma rítmica complexa, mas, ao mesmo tempo, complementar.

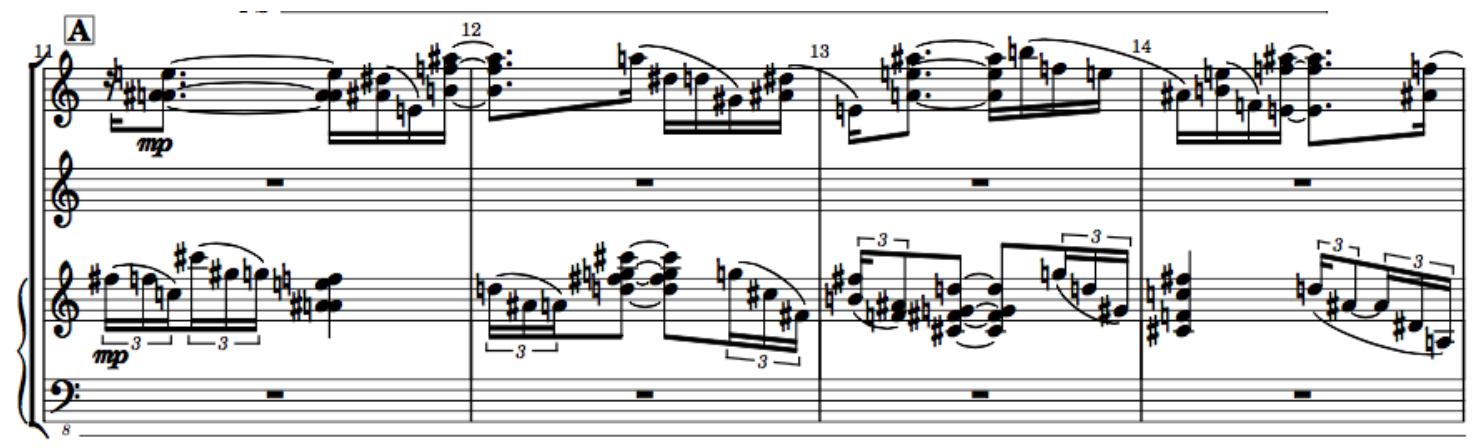

Fig. 7: Letra A

O movimento vai explorar diversas variações da mesma ideia de contraste rítmico entre dois planos. Na Fig. 8 pode ser observada a exploração de outra polirritmia (quintinas $x$ sextinas).

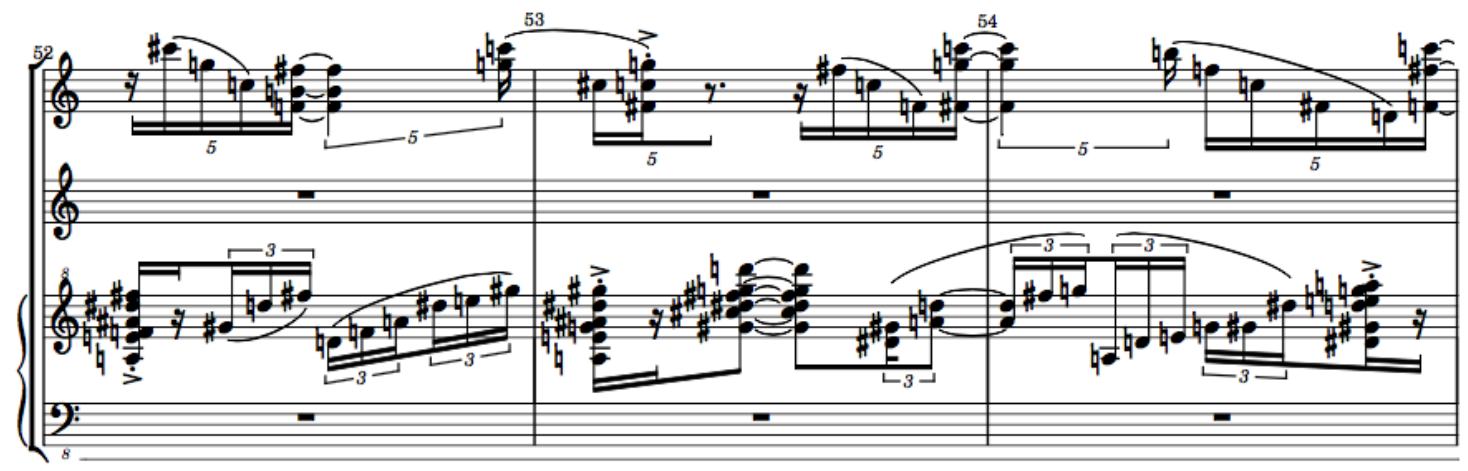

Fig. 8: Letra G

O princípio de referência para definir as diversas variações rítmicas baseia-se na presença de uma determinada "velocidade" na textura, assegurada por um tipo de figura rítmica, mas, ao mesmo tempo, em contextos sempre renováveis. Há três andamentos na peça, com a semínima equivalendo-se a 80, 96 e 120 MM. No trecho dos compassos 11 a 15, onde a semínima vale 80 MM, a velocidade 480 MM está assegurada pelas sextinas do piano. Entre os compassos 69 a 73, onde a semínima vale 96 MM, a velocidade 480 MM está associada às quintinas do vibrafone. Por sua vez, entre os compassos 82 
a 88 , onde a semínima vale $120 \mathrm{MM}$, a velocidade $480 \mathrm{MM}$ está associada às semicolcheias do piano. A ideia é manter presente a velocidade de $480 \mathrm{MM}$, mas sempre contraposta a outras velocidades diferentes, respectivamente 320, 384 e 360 MM, para os trechos discutidos.

\section{VI - en(tre)curso(s)}

A primeira imagem que me guiou quando comecei a planejar a composição da peça en(tre)curso(s) ${ }^{6}$ foi a de uma transformação gradual do timbre no decorrer de toda a peça. A peça foi concebida como uma sucessão de blocos, cada um relativamente homogêneo do ponto de vista da sonoridade. Ao mesmo tempo, a coloração deveria mudar de um bloco para outro, de maneira gradual. O plano inicial foi partir de uma sonoridade com predomínio de madeiras e chegar a outra baseada em instrumentos de metal.

Outra ideia importante, ligada à forma, foi pensar uma narrativa formada por três materiais entrelaçados, cada um deles evoluindo de modo independente no tempo. $O$ nome da peça reflete essa ideia: os parênteses separam "tres" de "en curso". Reforçando essa ideia de cruzamento de processos, há também três instrumentistas que entrelaçam suas linhas nas texturas dos diversos blocos.

A primeira versão da peça foi tocada em junho de 2019, e uma segunda versão, em novembro do mesmo ano. Para se chegar a algumas escolhas dessa versão final, foram necessários inúmeros cortes e alterações, a partir da experiência da montagem/performance da mesma. Os instrumentistas foram de grande importância nesse processo, com diversas sugestões que foram acolhidas no resultado final.

\begin{tabular}{|l|l|l|l|l|l|l|l|l|l|l|l|l|l|l|l|l|} 
A1 & A2 & A3 & B1 & A4 & A5 & B2 & A6 & B3 C1 & A7 & A8 & C2 & A9 A & A10 \\
\hline & & & & & & & & & & & & & & & \\
\hline
\end{tabular}

Fig. 9: Esquema dos materiais na sequência formal

A Fig. 9 ilustra a distribuição dos três materiais no tempo. As extensões de cada bloco foram calculadas proporcionalmente às durações de cada seção em uma performance da peça.

O material A é o mais importante, atravessando todo o percurso formal. $B$ e $C$ têm função de contraste. Os timbres de B e C são fixos e contrastantes: 2 marimbas e woodblocks para B (madeiras), contra um grupo de vibrafone, tubular bells, crotales, triângulos e gongo (metais), para C. Os timbres de A evoluem progressivamente no tempo:

- 2 marimbas;

- 2 marimbas e vibrafone;

- 2 marimbas e vibrafone;

- 2 marimbas e almglocken;

- 2 marimbas e almglocken;

6 en(tre)curso(s) para três percussionistas (marimbas, vibrafone, tubular bells, woodblocks, almglocken, pratos, gongo, tantã, brake drums, crotales, triângulos). 
- vibrafone, pratos, crotales e triângulos;

- vibrafone, brake drums e triângulos;

- vibrafone, pratos, crotales;

- almglocken, brake drums e triângulos;

- almglocken, pratos e crotales.

Os contrastes de sonoridade entre as seções resultam não apenas das mudanças nas combinações de instrumentos, mas também dos modos de ataque (baqueta/ arco) e do tipo de textura. Por exemplo, os pratos podem ser utilizados para rulos, golpes, raspagens etc. Assim, em situações de repetições de instrumentos, há sempre uma mudança de sonoridade obtida por outro recurso. Por exemplo, a repetição dos almglocken nos dois blocos finais do material A está relacionada a uma mudança de baqueta, o que provoca completa alteração do colorido (inicialmente uma baqueta de metal, em seguida uma de ponta de borracha).

A composição do material A de en(tre)curso(s) será abordada em três etapas, discutindo ritmo, harmonia e texturas.

\section{VI.1 RITMO}

O ponto de partida foi o início da peça The Axe Manual (BIRTWISTLE, 2001), para piano e percussão. Fiz uma análise rítmica da parte do piano, considerando, essencialmente, a distância entre ataques nos 16 compassos iniciais. Transcrevendo as durações em número de semicolcheias, obtém-se a seguinte sequência numérica: 81251612 451243153123412531114334612661117.

Para detectar a presença de padrões, recorri à ideia de dividir as durações em campos duracionais, abrangendo grupos de durações curtas (1 a 2 semicolcheias), médias (3 a 6) e longas (7 a 8). Os padrões detectados apresentam duas partes: início e continuação. O início é caracterizado por um grupo de durações curtas: (1 2) ou (1 1 1). A continuação é mais variada, apresentando de 2 a 5 durações médias. Eventualmente, uma das durações médias pode ser precedida por um valor curto (1).

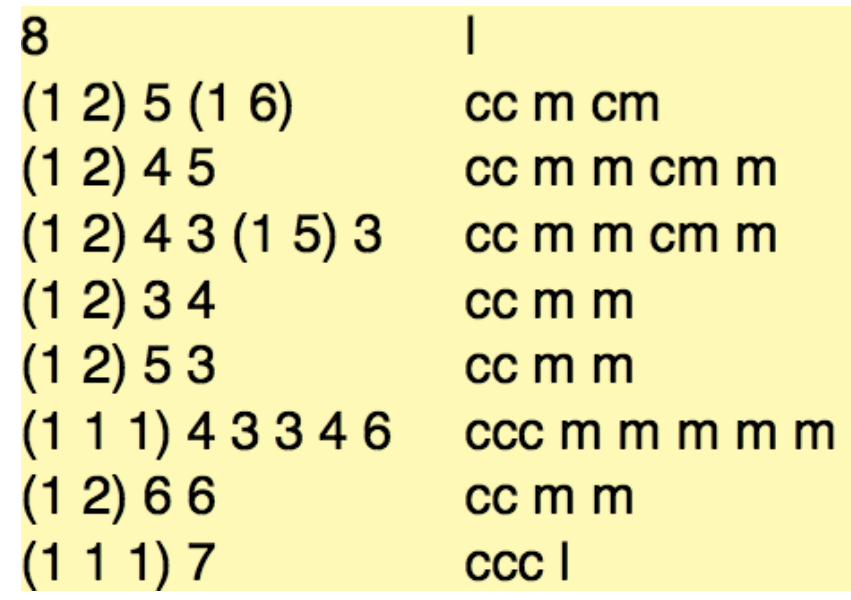

Fig. 10: Padrões de durações curtas (c), médias (m) e longas(I) 
A tarefa do algoritmo criado (software PWGL) foi gerar sequências variadas de padrões, respeitando as regras acima definidas. $O$ algoritmo gerou três blocos de oito compassos para referência na composição do material $A$. Essas linhas rítmicas foram utilizadas na construção das texturas de modo flexível, ora fragmentadas, ora com alterações. Além disso, cada ponto da linha temporal poderia disparar eventos em mais de um plano da textura, o que agrega ao processo uma dimensão polifônica. A linha funciona como um esqueleto temporal que vai recebendo camadas de sonoridade superpostas.

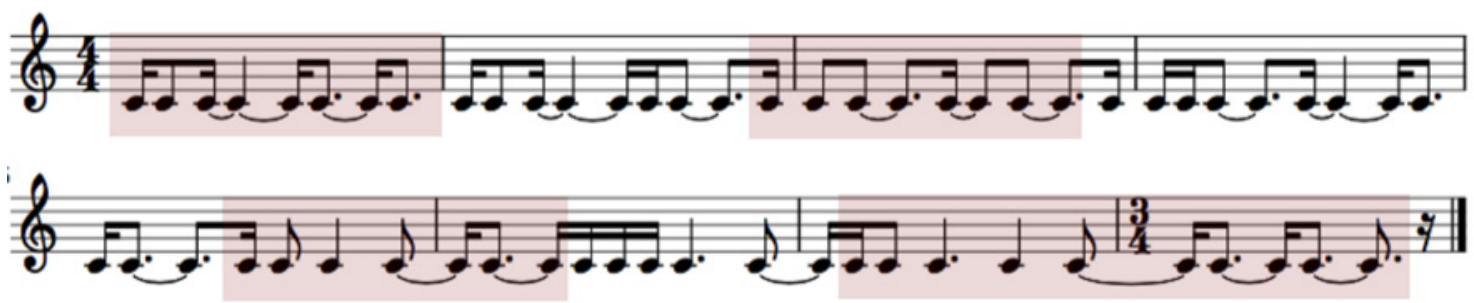

Fig. 11: Trecho gerado pelo algoritmo, evidenciando os padrões

\section{VI.2 - HARMONIA}

A harmonia do material A utiliza uma sequência de hexacordes (conjuntos de 6 classes de altura) que são distribuídos entre os planos das texturas de cada bloco. Esses acordes são formados pela combinação de um tetracorde fixo (4-9) - c c\# f\# g - e duas notas adicionadas. As notas adicionadas, por serem aleatórias, criam alguma variedade no colorido intervalar do acorde. A sequência utilizada consiste de 18 acordes diferentes, seguindo algumas regras:

- podem ser utilizados todos os hexacordes que contêm internamente o tetracor de 4-9, em qualquer transposição;

- há sempre três notas comuns entre dois acordes seguidos;

- há 11 ou 12 notas diferentes combinando-se três acordes seguidos.

O objetivo dessas regras foi garantir uma certa continuidade sonora, com redundância de algumas alturas, mas ao mesmo tempo preservando certa variedade na sequência. Naturalmente, controlam-se apenas as classes de altura, ficando o registro definido em função das características dos diferentes gestos presentes nas texturas de cada bloco. 


$\begin{array}{lll}\text { nome } & \text { transp } & \text { lista de alturas } \\ 6-5 A & 9 & (03491011) \\ 6-Z 6 & 2 & (234789) \\ 6-7 & 0 & (012678) \\ 6-Z 12 A & 5 & (0567911) \\ 6-Z 13 & 3 & (3467910) \\ 6-Z 17 A & 6 & (1267810) \\ 6-18 A & 11 & (0146711) \\ 6-30 A & 3 & (0346910) \\ 6-Z 38 & 1 & (123489) \\ 6-Z 50 & 1 & (1257810) \\ 6-Z 38 & 10 & (01561011) \\ 6-30 B & 3 & (0356911) \\ 6-18 B & 8 & (2348911) \\ 6-Z 17 B & 1 & (125789) \\ 6-Z 13 & 5 & (0568911) \\ 6-Z 12 B & 3 & (3468910) \\ 6-7 & 1 & (123789) \\ 6-Z 6 & 6 & (0167811)\end{array}$

Fig. 12: 18 acordes

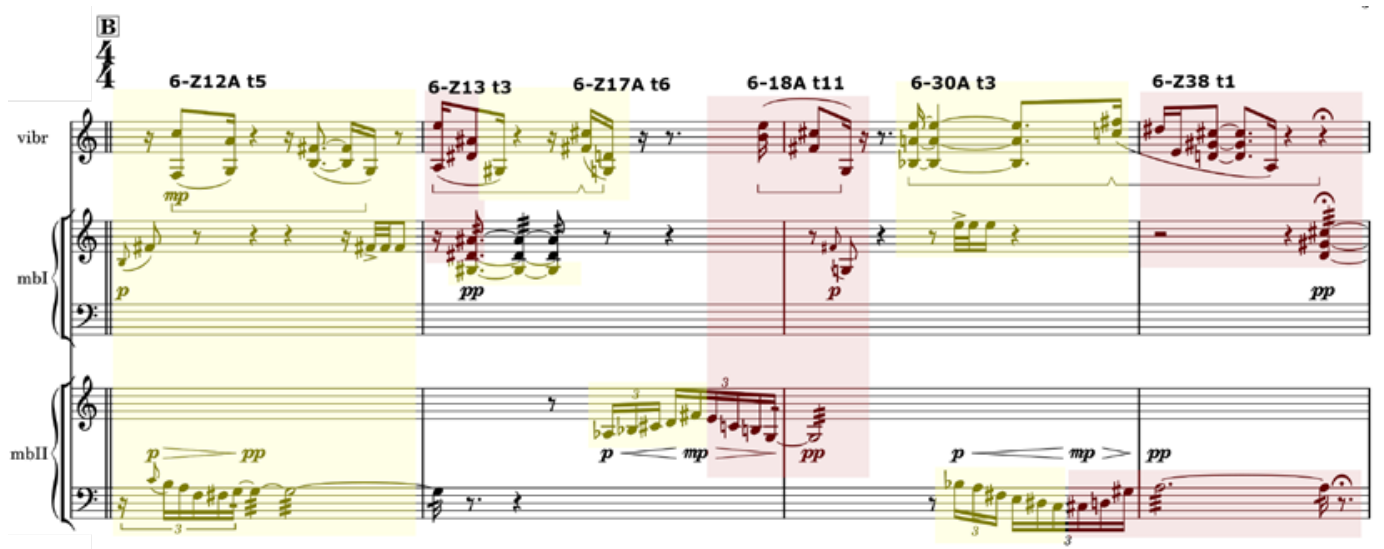

Fig. 13: en(tre)curso(s) (compassos 16-19)

A Fig. 13 ilustra um trecho da partitura (compassos 16-19) de en(tre)curso(s). 0 ritmo das partes superiores - respectivamente, vibrafone e marimba I - é diretamente extraído dos compassos iniciais da Fig. 11. A parte inferior - marimba II - tem ritmo independente. Pode-se dizer que os gestos melódicos da marimba II são disparados por alguns ataques dos outros instrumentos.

A harmonia também está indicada na Fig. 13 - nomes dos conjuntos e transposição - e pode ser comparada com a lista de acordes da Fig. 12, onde as notas estão representadas por números. Os acordes do trecho em questão correspondem ao fragmento que se inicia na quarta linha da Fig. 12. 


\section{VI.3 - TEXTURAS}

A principal ideia do material revela-se na evolução das texturas dos blocos, associada à mudança de instrumentação. $O$ material $A$ aparece em 10 blocos de en(tre) curso(s). A Fig. 14 ilustra dois compassos de cada bloco.
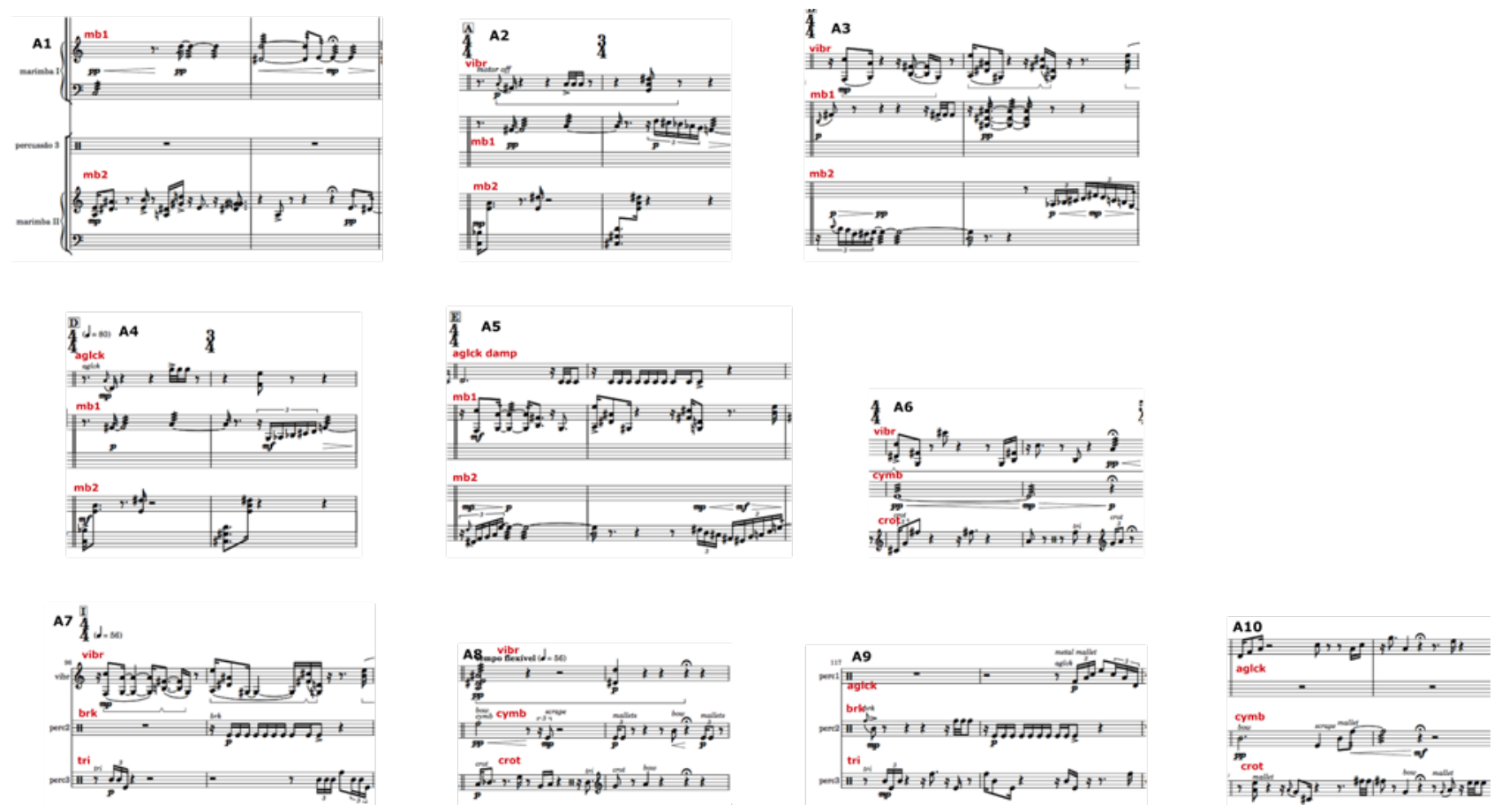

Fig. 14: 10 blocos do material $A$

Os blocos A1, A2 e A3 apresentam um crescendo de densidade e uma mudança dos gestos entre os instrumentos. O plano principal alterna-se entre as marimbas em A1, fixa-se na marimba II em A2 e migra para o vibrafone em A3. Os gestos escalares surgidos na marimba I em A2 migram para a marimba II em A3.

O bloco A4 retoma a textura de A2, substituindo o vibrafone pelos almglocken. A5 retoma $A 3$, mas introduz um elemento novo, a nota pulsada em um almglocken abafado.

A6 caracteriza-se pela tímbrica exclusivamente metálica - vibrafone, pratos e crotales. A7 sugere um retorno variado de $\mathrm{A} 5$, mas a nota repetida é realizada pelos brake drums. Por sua vez, o gesto escalar é substituído por uma figuração em tercinas nos triângulos. A8 recorda $A 6$, mas acrescenta um componente novo, o uso do arco como modo de produção sonora de pratos e crotales.

A9 retoma $A 7$, trocando ideias e instrumentos, o plano principal migra do vibrafone para os triângulos, o plano das tercinas desloca-se dos triângulos para os almglocken (baqueta metálica), e a nota repetida permanece nos brake drums.

A10 retoma o arco como modo de produção sonora, mas o elemento novo é a linha principal nos almglocken, tocados com baqueta de ponta de borracha.

A ideia geral é de uma transformação progressiva, com retomada de elementos anteriores para ajudar a memória no reconhecimento do material em questão. 
Os materiais B e C agem como contraste, com relação ao A. Não vou me deter em discutir os detalhes de sua organização. Apenas destaco a presença de uma rítmica fortemente pulsada em B e, por oposição, outra extremamente flutuante em C.

\section{VII - Considerações finais}

Há muitos desafios no trabalho do compositor. Talvez o maior deles seja justamente a oscilação entre um trabalho construtivo, de natureza técnica, onde modelos de características diferentes são combinados e entrelaçados de modo a produzir um objeto complexo (que será posteriormente interpretado na performance), e a experiência da escuta com seu lastro expressivo, que é o momento em que a obra se completa. Embora os caminhos da composição sejam múltiplos, há que se destacar que, na tradição da música de concerto, essa dimensão construtiva vem desempenhando um papel relevante nos últimos séculos. A ideia central é que, controlando-se as formas sonoras, se controlam também os vetores expressivos na escuta. Entretanto, aprendemos no século XX que, assim como um texto sempre ultrapassa as intenções do autor e pode criar sentidos imprevistos, a experiência da escuta musical nunca é completamente controlada. Se há riscos evidentes nesse fato - um exemplo recorrente é a experiência de não sentido diante de uma obra contemporânea -, por outro lado, essa abertura é justamente uma oportunidade para a renovação, uma porta por onde a imaginação pode escapar de um mundo predefinido e alçar voo em direção ao desconhecido.

O processo criativo supõe, justamente, essa sensibilidade de perceber algo diferente à margem do território que foi cartografado. Seja uma nuance imprecisa, uma luminosidade sutil ou uma força de expansão indefinida, há traços expressivos que se insinuam no material musical. Cabe ao compositor tornar sensível esse mundo interior.

\section{Referências}

AGON, C.; ASSAYAG, G.; BRESSON, J. OpenMusic: software. Versão 6.15. [S. l.: s. n.], 1998-2020. Disponível em: https://openmusic-project.github.io/. Acesso em: 29 mar. 2020.

BIRTWISTLE, H. The Axe Manual. London: Boosey \& Hawkes, 2001.

CANNAM, Chris; LANDONE, Christian; SANDLER, Mark. Sonic Visualiser: an open source application for viewing, analysing, and annotating music audio files. In: ACM MULTIMEDIA 2010 INTERNATIONAL CONFERENCE, 2010. Proceedings [...]. [S. l.: s. n.], 2010. p. 1467-1468.

CARTER, E. A Symphony of Three Orchestras. New York: Associated Music Publishers, 1978. 
DUCHEZ, M. E. L'évolution scientifique de la notion de matériau musical. In: BARRIÈRE, J.-B. (ed.). Le timbre, métaphore pour la composition. Paris: Christian Bourgois, 1991. p. 47-81.

HUBER, K. Complete Cello Works. Compositor: Klaus Huber. Intérprete: A. Descharmes. [S. l.]: Aeon, 2010. 1 CD.

LAURSON, M.; KUUSKANKARE, M.; SPROTTE, K. PWGL: software. Versão RC 19. [S. l.: s. n.], 2006-2017 Disponível em: http://www2.siba.fi/PWGL/downloads.html. Acesso em: 29 mar. 2020.

LINK, J. F. Long-range polyrhythms in Elliott Carter's recent music. Tese (Doutorado em Música) - City University of New York, New York, 1994. 